\title{
US throws money at TSE research
}

Suddenly, the United States government is very interested in prions. The Department of Health and Human Services (HHS) has announced major new plans to study and combat bovine spongiform encephalopathy (BSE) and other transmissible spongiform encephalopathies (TSEs). In addition to stringent new Food and Drug Administration (FDA) rules restricting blood donation, the government published an action plan that proposes to double funding for basic research into TSE diseases, and floated the idea of multimillion-dollar cash prizes to be awarded to the first research teams to develop effective TSE diagnostic tests.

Government spending on prion diseases last year was \$28.3 million, \$23.9 million of which was distributed by the National Institutes of Health (NIH). The 2002 HHS budget proposal will include $\$ 48.1$ million in total funding for prion research, with the li-

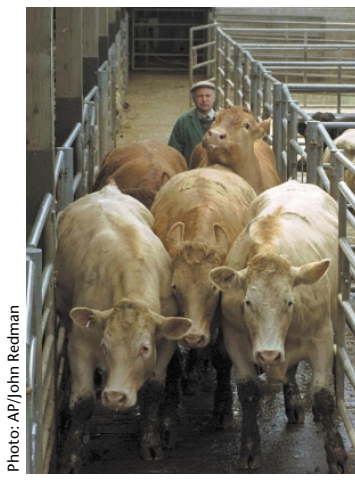

University. Aside from concerns about the initiative will increase the number of prion research facilities. About six labs nationlab have received approval to work with BSE. containment lab appears to have eliminated one high-profile researcher from the on's share again going to the NIH. In addition, acting NIH director Ruth Kirchstein has allocated $\$ 5$ million in discretionary funding to boost TSE research this year. New grants for TSE research will run for 5-10 years, rather than the $4-5$ years typical of most NIH grants, to allow for the long-term experiments required in prion research.

The dramatic new plans seem all the more sudden given that US stock herds are presumed to be free of BSE and no cases of BSE or its lethal human counterpart, variant Creutzfeldt-Jakob disease (vCJD), have been reported in the US. Last month, Japan announced the first case of BSE in Asia when a dairy cow tested positive for the disease.

Assistant Surgeon General Arthur Lawrence insists there is no cause for alarm, but explains that "...prion diseases were worrisome enough to precipitate an immediate look at this in a very serious light." According to Lawrence, the current action plan grew out of a meeting between HHS secretary Tommy Thompson, president of the American Red Cross Bernardine Healey and prion researchers Stanley Prusiner of the University of California at San Francisco (UCSF) and Pierluigi Gambetti of Case Western Reserve US blood supply, half of which is collected by the Red Cross, HHS is hoping that the wide study scrapie and vCJD, but only Prusiner's lab at UCSF, the Institute for Basic Research in Staten Island and an NIH

Indeed, the expense of establishing a BSE field already. Although this journal reported in March that Robert Gallo, co-discoverer of HIV and director of the Institute for Human Virology (IHV) in Baltimore, had agreed to work with the Illinois company Prion Developmental Laboratories (PDL) on a $\$ 4.2$ million project to develop a rapid BSE diagnostic test (Nature Med. 7, 261; 2001), David Grosky, chairman and CEO of PDL, now says that

PDL has developed a postmortem BSE test in its own labs, which Grosky claims is much cheaper and faster than tests currently in use in Europe: "We'll be able to sell it for \$2-5, versus the $\$ 20-100$ prices for current tests"; but, he continues, "the goal of our company is a pre-death test for both humans and animals." Three postmortem BSE tests have been approved in Europe, but none have been approved by the US and no test is available for vCJD.

Development of an effective test for human prion diseases is the subject of one of the most unusual aspects of the new HHS plan: a $\$ 1$ million prize for the first demonstration of such a test, and a $\$ 5$ million prize for the first test to win FDA approval. This is the first time HHS has considered offering such an incentive for research, but Lawrence stresses that the prize is currently only an idea, which the department was due to discuss with academic and corporate researchers at a 24 September meeting in Washington, DC.

With or without the prize, prion researchers are hopeful that the HHS plan will draw more scientists to the field. "This will raise the level of consciousness within the scientific community and attract highlevel scientists who have either not been aware or didn't think it was worth getting into the prion field," says Robert Petersen, professor of pathology at Case Western Reserve.

\section{Alan Dove, Philadelphia}

\section{Klausner quits}

Following weeks of speculation, Richard Klausner announced last month that he was quitting his job as director of the National Cancer Institute ( $\mathrm{NCl})$ after six years. Rumors abound as to his reasons for leaving the largest group within the $\mathrm{NIH}$, and if anything, these were enhanced by his revelation that he is leaving to lead a "theoretical organization" within the Case Foundation.

Klausner was a highly successful and charismatic director. He is widely credited with expanding NCl's range of work; for example, by promoting minority research, epidemiological studies and scaling-up clinical trials. Last year he presided over a research budget of $\$ 3.8$ billion. Yet there is speculation that he clashed with the Bush administration over issues such as salary increases for $\mathrm{NCl}$ executives and that this precipitated his departure.

As head of the new Case Institute, funded by Steve Case, chairperson of AOL Time Warner, Klausner will coordinate "new ideas and solutions across the boundaries of traditional scientific disciplines." Examples include a program aimed at linking biology, nanoand micro-technology, chemistry and information sciences to transform health, disease and environmental research.

Karen Birmingham, London 